\title{
Neurological complications after a single severe exposure to toluene di-isocyanate
}

\author{
PAMELA M.LE QUESNE, A. T. AXFORD, C. B. MCKERROW*, \\ and A. PARRY JONES \\ MRC Toxicology Unit, Carshalton, Surrey and MRC Pneumoconiosis Unit, Penarth, \\ Glamorgan
}

\begin{abstract}
Le Quesne, P. M., Axford, A. T., McKerrow, C. B., and Parry Jones, A. (1976). British Journal of Industrial Medicine, 33, 72-78. Neurological complications after a single severe exposure to toluene di-isocyanate. A total of 23 men complained of neurological symptoms after a single severe exposure to toluene di-isocyanate. Effects of exposure were immediate in five men and consisted of euphoria, ataxia, and loss of consciousness. These men and nine others complained of headache, difficulty in concentration, poor memory, and confusion during the next three weeks. Four years later it was found that nine further men had experienced symptoms that they had not been aware of at three weeks. In all, 13 men still complained of poor memory, personality change, irritability, or depression after four years. Psychometric testing showed a selective defect for relatively long-term recall in those with persistent symptoms at four years.
\end{abstract}

In November 1967 a group of firemen were heavily exposed to toluene di-isocyanate (TDI) while fighting a fire in a factory where polyurethane foam was manufactured. Details of the fire and the degree of exposure to TDI are given in another paper (Axford et al., 1976) in which the gastrointestinal and respiratory symptoms in these men are described. In summary, 31 of the 35 men who were seen after the fire developed tightness in the chest, dyspnoea, or cough; 16 men complained of nausea, vomiting, or abdominal pain. These various symptoms were present either at the time of the fire or during the next day. The present paper describes the neurological syndrome which developed in some of the men. A preliminary report of the early toxic complications has already been published (McKerrow, Davies, and Parry Jones, 1970).

Acute respiratory symptoms after exposure to TDI have been recognized for some time (Fuchs and Valade, 1951; Gandevia, 1963) and it has been suggested that long-term effects may also occur (Munn, 1965). Neurological complications have not previously been described.

*Dr McKerrow died in July 1972

\section{Subjects}

Altogether 23 men who were involved in the fire complained of neurological symptoms at some time and were interviewed and examined on one or more occasions during the four years after the fire. Their ages are shown in Table 1 . Half of them were in their fourth decade at the time of the fire. Two men were full-time employees in the fire service, and the remainder had other jobs in addition to part-time fire service activities.

Seventeen men were seen three weeks after the fire with complaints that suggested a possible neurological origin. The symptoms were considered to be important in 14 of the 17 men. A further review was undertaken at four years, when 18 men were seen; five of the original men were lost to follow-up, but others had reported similar complaints in the intervening years. Altogether 13 men were thought to be still affected. The symptoms and their incidence are shown in Table 1.

Immediate neurological effects

Five men developed symptoms while the fire was in progress (Table 1). They said that they felt as if they 
were drunk, one as if he had taken 5 litres of beer and another as if he had drunk half a bottle of whisky. They laughed unreasonably and were quite unafraid of the fire. They were aware of staggering about and were seen to be doing so by their colleagues. One man who lost his balance and fell over on several occasions thought it a joke that he was unable to aim his hose in the right direction. Later his limbs were seen by his colleagues to be shaking intermittently for about 10 minutes. This man and two others who transiently lost consciousness had no memory of being taken to hospital by ambulance. None of these men had a headache at the time of the fire, but two complained of a dull pain in the head the next day.

Early neurological effects (up to three weeks)

The complaints made by three of the 17 men were not thought to be of importance. The remainder of the men complained of difficulty in concentrating, confusion, poor memory, headache, irritability, or depression (Table 1).

In the five patients who developed immediate effects the initial euphoria had subsided by the next day. They and nine others developed new symptoms during the next few days. They had been given three days off duty and it is difficult to be certain if symptoms were delayed or whether they were not noticed until the men resumed their normal activities. In some instances an abnormality was first noticed by a relative or colleague and not by the patient himself.

Difficulty in concentration was the commonest complaint, causing problems at work and at home. Patients found they were unable to read a book or even to watch television. Several patients described a feeling of being detached and as if in a stupor. As a result they described episodes of odd behaviour, classified in Table 1 as confusion. For example, one man attempted to shave with his toothbrush, another tried to open his garage with the wrong key, another flushed the water closet before using it.

Ten men also complained of poor memory, for example forgetting where a car was parked, where they had put things down, why they had gone shopping, or a telephone number they were trying to dial. An interior decorator was unable to remember measurements and therefore cut wallpaper to the wrong size. A carpenter had similar memory problems which caused difficulty in cutting wood correctly.

Seven men complained of a dull headache during the week after the fire. Two were impotent for two weeks. Others were irritable or depressed. Two men had some difficulty with their balance during the subsequent week and two complained of shakiness and intermittent feelings of numbness and pins and needles in the extremities.
Symptoms were at their worst during the second week after the fire. By the time of interview they were all improving.

Abnormalities on neurological examination were slight. Six men had slight ataxia of gait, particularly on heel-toe walking but in none was this severe. In the two patients who complained of paraesthesiae and sensory loss in the limbs, there was subjective alteration to pin prick over the hands and feet but no other sensory abnormality. In one of these, who will be described later, this was not thought to be organic in origin.

Electroencephalograms were recorded in nine men during the two weeks after the fire. Records from eight men were normal. Some generalized underlying slow activity was present in the record from Case 14. This was unchanged when the examination was repeated three months later, and its significance is doubtful.

\section{Long-term neurological effects (three weeks to four years)}

Eighteen men who were involved in the fire were seen four years later, twelve of them had been seen at the first review. Six men, who were not seen on the first occasion because they had no symptoms at that time subsequently complained of possible neurological symptoms and were therefore included in the review at four years. The incidence of the various symptoms is shown in Table 1.

The commonest complaint was poor memory, and this was the sole complaint of 10 men. Others complained of personality change, difficulty in concentration, irritability, or depression. Several wives complained about a change in their husband's behaviour.

Ten men complained that their symptoms interfered with their work. Six were able to continue in the same occupation but with more difficulty than previously. For example a decorator aged $\mathbf{4 0}$ years, who was pensioned from the fire service because of his disability, was unable to work more than five hours a day because of breathlessness and difficulty in concentrating. He found great difficulty in organizing his activities and his earnings had dropped substantially. A shopkeeper aged 41 years, had to make lists of goods to order, and a man aged 62 years, who lectured to the fire service had to use notes. They had been able to do all these things easily without written help before the fire. Many men said that they needed to keep a detailed diary for the first time.

Four men were in less demanding employment. Two of them had been pensioned out of the fire service. They both had long periods off work during the first two years after the fire.

At the time of review none of the patients appeared to be deteriorating, although some expressed 
TABLE 1

InCidence of NeUrological AbNormalities

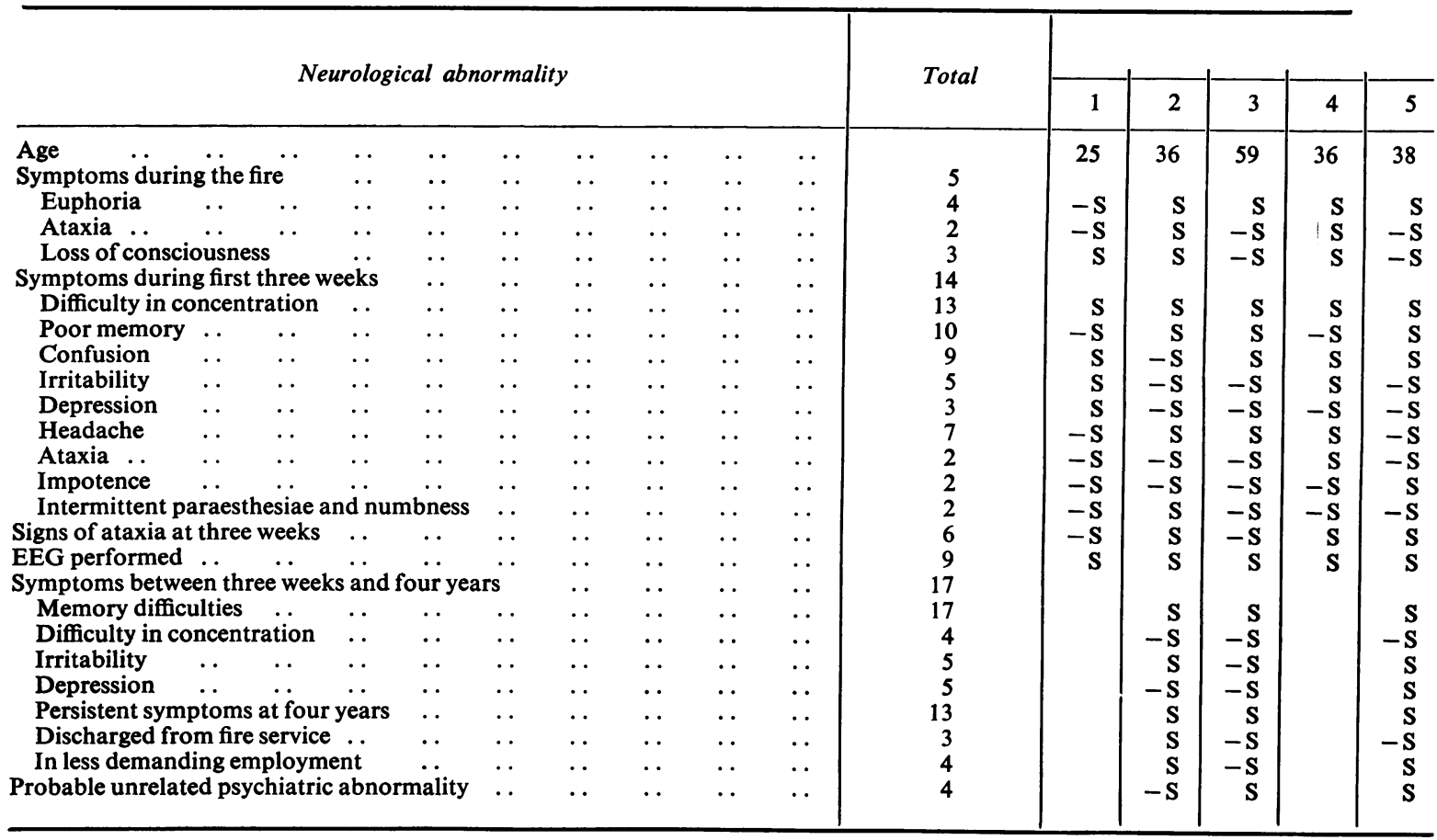

Five patients were lost to follow-up at four years

$\mathrm{S}=$ symptom; $-\mathrm{S}=$ no symptoms

increasing anxiety about the failure of full recovery. All had been at their worst during the weeks after the fire, and gradually improved. Four men (Cases $9,14,21,22$ ) had become symptom-free during periods ranging from six months to three years. It is doubtful whether any further neurological change was still taking place in any of the men.

On neurological examination no abnormal physical signs were detected, except persistent distal sensory impairment in one man, which will be discussed below.

\section{Case histories}

Case 3: full time fire service employee

This 59-year-old man was near the leaking tank of TDI for about four hours during the fire. When driving away from the fire he felt euphoric, but by the next day had recovered. On returning to work three days later, his secretary noticed that he made frequent mistakes when dictating. His memory of the next few days is hazy; he had great difficulty in concentrating, forgot well-known names, and had intermittent occipital headache for a week. He gradually improved during the next nine months. When seen at four years his only complaint was of poor memory. He had difficulty remembering people's names and the contents of documents he read, and had to use notes for lecturing. He was not depressed. He had no abnormal neurological signs at either examination.

He experienced some respiratory symptoms after the fire. The next day he had a sore throat, tightness of the chest, and developed a cough with sputum for a few days. He had no further respiratory symptoms.

\section{Case 7: carpenter}

At the time of the fire this 31-year-old man was involved in attempts to close a leaking valve on a tank of TDI. He wore breathing apparatus, but his uniform became soaked in liquid TDI and for a time he lay in liquid that was covering the floor. He noticed no ill effects during the fire or in the next few days. When he started work again, a week after the fire, he found that he made unaccustomed mistakes in measuring and cutting wood. He felt depressed, particularly in the mornings, and irritable. During the next week he improved and by the time of the first examination he said he felt quite normal.

When interviewed four years later he complained that, although he had improved within a few weeks of the fire, he soon realized that he was not completely normal. He was no longer able to remember telephone numbers, always had to take a list when shopping, and had difficulty with people's names. His wife complained that he was unreasonably irritable. He was depressed at times. Having previously been sociable, he now preferred 


\begin{tabular}{|c|c|c|c|c|c|c|c|c|c|c|c|c|c|c|c|c|c|}
\hline \multicolumn{17}{|c|}{ Case nos. } & \multirow[b]{2}{*}{23} \\
\hline 6 & 7 & 8 & 9 & 10 & 11 & 12 & 13 & 14 & 15 & 16 & 17 & 18 & 19 & 20 & 21 & 22 & \\
\hline 36 & 31 & 57 & 37 & 47 & 54 & 51 & 34 & 44 & 37 & 37 & 33 & 49 & 55 & 34 & 43 & 47 & 57 \\
\hline $\begin{array}{r}S \\
S \\
-S \\
-S \\
-S \\
-S \\
-S \\
-S \\
-S \\
-S \\
-S \\
-S\end{array}$ & $\begin{array}{r}-S \\
S \\
-S \\
S \\
S \\
-S \\
-S \\
-S \\
-S \\
-S \\
-S\end{array}$ & $\begin{array}{r}\mathbf{S} \\
\mathbf{S} \\
\mathbf{S} \\
-\mathbf{S} \\
\mathbf{S} \\
\mathbf{S} \\
\mathbf{S} \\
-\mathbf{S} \\
-\mathbf{S} \\
\mathbf{S} \\
-\mathbf{S}\end{array}$ & $\begin{array}{r}S \\
S \\
S \\
S \\
-S \\
S \\
-S \\
-S \\
-S \\
-S \\
-S \\
S\end{array}$ & $\begin{array}{r}S \\
-S \\
-S \\
-S \\
-S \\
-S \\
S \\
-S \\
-S \\
-S \\
-S \\
-S\end{array}$ & $\begin{array}{r}S \\
\mathbf{S} \\
-\mathbf{S} \\
-\mathbf{S} \\
-\mathbf{S} \\
\mathbf{S} \\
-\mathbf{S} \\
-\mathbf{S} \\
-\mathbf{S} \\
-\mathbf{S} \\
-\mathbf{S}\end{array}$ & $\begin{array}{r}\mathbf{S} \\
\mathbf{S} \\
\mathbf{S} \\
\mathbf{S} \\
-\mathbf{S} \\
-\mathbf{S} \\
-\mathbf{S} \\
-\mathbf{S} \\
-\mathbf{S} \\
\mathbf{S} \\
\mathbf{S}\end{array}$ & $\begin{array}{r}S \\
S \\
-S \\
-S \\
-S \\
-S \\
-S \\
-S \\
-S \\
-S \\
S\end{array}$ & $\begin{array}{r}\mathbf{S} \\
-\mathbf{S} \\
\mathbf{S} \\
-\mathbf{S} \\
-\mathbf{S} \\
-\mathbf{S} \\
-\mathbf{S} \\
\mathbf{S} \\
\mathbf{S} \\
\mathbf{S} \\
\mathbf{S}\end{array}$ & $\begin{array}{l}-S \\
-S \\
-S \\
-S \\
-S \\
-S \\
-S \\
-S \\
-S \\
-S \\
-S\end{array}$ & $\begin{array}{l}-S \\
-S \\
-S \\
-S \\
-S \\
-S \\
-S \\
-S \\
-S \\
-S \\
-S\end{array}$ & $\begin{array}{l}-S \\
-S \\
-S \\
-S \\
-S \\
-S \\
-S \\
-S \\
-S \\
-S \\
-S\end{array}$ & & & & & & \\
\hline $\begin{array}{r}S \\
S \\
-S \\
-S \\
S \\
S \\
-S \\
-S\end{array}$ & $\begin{array}{r}\mathbf{S} \\
\mathbf{S} \\
\mathbf{S} \\
\mathbf{S} \\
\mathbf{S} \\
-\mathbf{S} \\
-\mathbf{S} \\
-\mathbf{S}\end{array}$ & $\begin{array}{r}\mathbf{S} \\
\mathbf{S} \\
-\mathbf{S} \\
\mathbf{S} \\
\mathbf{S} \\
-\mathbf{S} \\
\mathbf{S} \\
\mathbf{S}\end{array}$ & $\begin{array}{r}S \\
-S \\
-S \\
-S \\
-S \\
-S \\
-S \\
-S \\
-S\end{array}$ & & & $\begin{array}{l}\mathbf{S} \\
\mathbf{S} \\
\mathbf{S} \\
\mathbf{S} \\
\mathbf{S} \\
\mathbf{S} \\
\mathbf{S} \\
\mathbf{S}\end{array}$ & & $\begin{aligned} & S \\
&-S-S \\
&-S \\
&-S \\
&-S \\
&-S \\
&-S \\
&-S\end{aligned}$ & $\begin{array}{r}S \\
-S \\
-S \\
-S \\
-S \\
-S \\
-S \\
-S\end{array}$ & $\begin{array}{r}S \\
-S \\
-S \\
-S \\
S \\
-S \\
-S \\
-S\end{array}$ & $\begin{array}{r}S \\
-S \\
-S \\
-S \\
-S \\
S \\
-S \\
-S \\
-S\end{array}$ & $\begin{array}{r}S \\
-S \\
S \\
S \\
S \\
-S \\
-S \\
-S\end{array}$ & $\begin{array}{r}S \\
-S \\
-S \\
-S \\
S \\
-S \\
-S \\
-S\end{array}$ & $\begin{array}{r}S \\
-S \\
-S \\
-S \\
-S \\
-S \\
-S \\
-S\end{array}$ & $\begin{aligned} & S \\
&-S-S \\
&-S \\
&-S \\
&-S \\
&-S \\
&-S \\
&-S \\
&-S\end{aligned}$ & $\begin{aligned} & S \\
&-S \\
&-S \\
&-S \\
&-S \\
&-S \\
&-S \\
&-S\end{aligned}$ & $\begin{array}{l}-S \\
-S \\
-S \\
-S \\
-S \\
-S \\
-S \\
-S\end{array}$ \\
\hline
\end{tabular}

to be alone. He no longer had enough patience or concentration to read a book. Despite these difficulties, he was in more highly paid employment than at the time of the fire. He had become a fire prevention officer for a private firm and had no difficulty with the responsibility or degree of authority needed for his job.

No abnormal neurological signs were found at either examination.

This man had no respiratory symptoms at the time of the fire, but during the next few days complained of tightness of the chest, cough, and nausea. During the next four years he complained of a productive cough and increased susceptibility to respiratory infection. He had no symptoms preceding the fire.

Case 18: self-employed greengrocer

During the fire this 49-year-old man spent many hours spraying the tanks of TDI to keep them cool. He was conscious of fumes and smell during this time.

He was unaware of any possible neurological abnormality until a few weeks after the fire and therefore was not examined at three weeks. His wife noticed that his memory was poor and she frequently had to remind him to do things. This symptom improved during the next year, but some difficulty remained. His wife also complained of his being irritable. He is no longer able to take full responsibility for running his business, as previously, and his wife has taken over much of the management.
He had no abnormal neurological signs.

At the time of the fire he complained of irritation of his eyes, nose, and throat and the next day complained of chest tightness and an unproductive cough with nausea. These symptoms lasted about one week. He continued to complain of a morning productive cough which had been present previously. However, he had more frequent respiratory infections during the next few years.

\section{Additional psychiatric features}

In four patients psychiatric complaints predominated. These were of a different nature from the complaints of irritability and depression which seemed to form part of the organic disorder. Two of these men had a history of psychiatric illness.

One man (Case 8) already had a reactive depression before the fire because his wife had been incapacitated by disseminated sclerosis. When seen at four years he was much less depressed but had difficulty with his memory and concentration similar to that of many of the other men. Depression was unduly prominent at four years in one other man (Case 5). He had been euphoric at the time of the fire and mildly confused at times for a few weeks thereafter. After four years he complained of some memory difficulty and headache. He had little spontaneous speech and was slow to answer questions. He had a dull expressionless face but no abnormal neurological signs. 


\section{Case 2: goods vehicle driver}

This 36-year-old man was heavily exposed to fumes in the building for several hours during the fire and became euphoric, ataxic, and lost consciousness. Healso developed nausea. He continued to complain of episodes of loss of consciousness, of numbness in the extremities, and of severe memory difficulty. He was admitted to hospital after one year. On examination, despite his limb symptoms, he was able to carry out all fine movements. Hypalgesia was present over the hands and feet; sensation was otherwise normal. Nerve conduction studies revealed normal sensory action potentials in the hands and a normal afferent volley in the lateral popliteal nerve. Episodes of loss of consciousness which were witnessed were not thought to be organically-determined. His electroencephalogram was normal. When seen four years after the fire his symptoms had improved slightly. He had changed his occupation to a less demanding one at a corporation refuse tip. The memory difficulties in this patient were similar to those of others in the group, but it was thought that many of his symptoms were not organic.

This man also developed respiratory complaints. After the fire he developed a cough and breathlessness on exertion which persisted. His cough was productive of sputum during each winter and he had several acute attacks of bronchitis.

\section{Case 12: electrician}

This 51-year-old man had had a nervous breakdown a year before the fire. He had become depressed and been off work for a few weeks. He was at the end of the building where the fumes were leaking during the fire. When seen three weeks after the fire he complained of difficulty with his memory and feelings of confusion. It was thought that a depressive reaction contributed to his symptoms. He had long periods off work during the first two years after the fire. He was very tense, nervy, and depressed. He complained of a poor memory, increased emotional lability, and a tendency to weep easily. After two years he changed his employment from that of electrician to messenger. His symptoms continued. On examination after four years his limbs were tremulous but he had no ataxia and, despite complaints of unsteadiness, his gait and balance were normal. It was concluded that this man had suffered a mild organic change, similar to many of the other men, but that his disability was accentuated by an unstable personality.

He also had respiratory symptoms. He experienced irritation of his eyes and throat during the fire and developed chest tightness the next day. He continued to have a productive cough with some breathlessness for about six months. He had several episodes of bronchitis during the winter months.

\section{Psychometric testing}

Psychometric testing using the Wechsler memory scale was carried out on 18 men four years after the fire. Of these, 13 were still clinically affected, four who had previously been affected were thought to have recovered completely, and the symptoms in one were not thought to be relevant. A group of 15 firemen from another part of the country was tested in a similar way. These men were volunteers from a nearby fire service which served a very similar population. Their social and educational backgrounds were thought to be similar. The results of psychometric testing in these men provided control values to compare with those of the affected firemen.

Memory quotient (MQ) was calculated for each man. The MQs averaged 101.9 for the exposed men and 105.9 for the control group (Table 2). This difference is not significant, nor is the difference between the control group and the group clinically still affected.

The Wechsler memory scale consists of seven tests, and it was decided to divide the tests into three groups, which test different memory functions:

1. Tests I, II, and III of stored memory, comprising tests of personal and current information, orientation, and mental control (counting).

2. Test $\mathrm{V}$ of short-term memory (digit retention).

3. Tests IV, VI, and VII of relatively long-term recall, comprising tests of logical memory, visual reproduction, and associated learning.

The results for the different groups of tests were examined separately. There was found to be no difference between the affected and the control men for tests of stored or short-term memory, but there were differences for the group of tests which examined relatively long-term recall.

Calculation of MQ incorporates a correction for age. This does not apply to individual subscores and therefore, in order to compare different groups, it was necessary to apply a correction for age. The mean age of the exposed men was 46.6 years (SD 9.35) and of the control group 39.4 years (SD 10.80). The mean age of all the subjects tested was 43 years and adjustments were made to this age. Age correction for the group of subtests for relatively long-term recall was made by using the weighted average of the regressions of the different groups, giving a loss of

TABLE 2

Results of Psychometric Testing. The Subtest for Relatively Long-term Recall is Shown

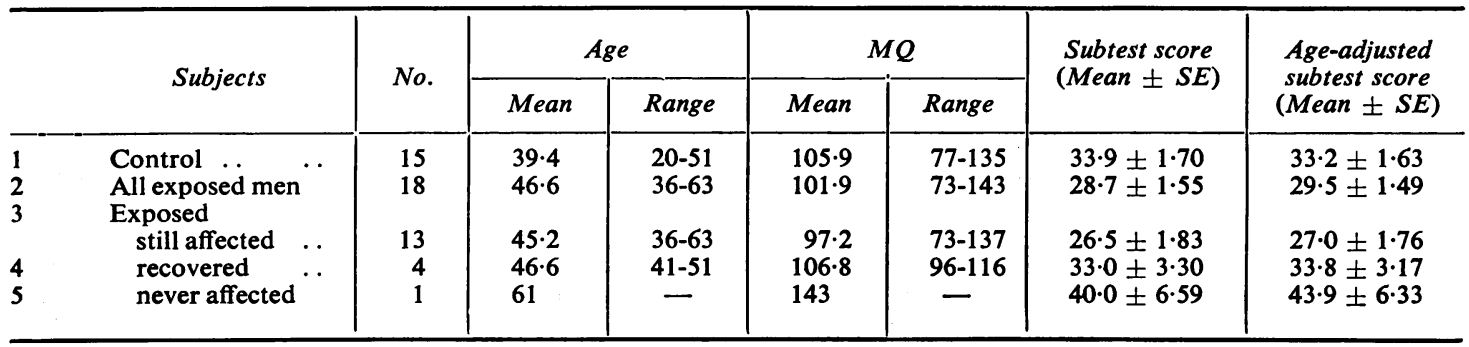


TABLE 3

Statistical Comparisons of Age-Adjusted Subtest Score for Groups of Men Shown in Table 2

\begin{tabular}{|c|c|c|c|c|c|}
\hline & Comparison & & Difference $\pm S E$ & Student's t test & Significance \\
\hline $\begin{array}{l}1 \mathrm{v} .2 \\
1 \mathrm{v} .3\end{array}$ & $\begin{array}{ll}\ldots & \ldots \\
\ldots & \ldots\end{array}$ & $\begin{array}{l}\ldots \\
\ldots\end{array}$ & $\begin{array}{l}3 \cdot 7 \pm 2 \cdot 21 \\
6 \cdot 2 \pm 2 \cdot 40\end{array}$ & $\begin{array}{l}1 \cdot 67 \\
2 \cdot 58\end{array}$ & $\begin{array}{l}0.20>P>0.10 \\
0.02>P>0.01\end{array}$ \\
\hline
\end{tabular}

$0 \cdot 22$ units of score per year of age. The results are shown in Table 2, and the results of statistical comparisons of the age-adjusted subtest score for the different groups of men are shown in Table 3. The difference between the control and all exposed men was not statistically significant. However when the control group was compared with the exposed group which was still affected clinically then the difference between the groups was significant.

In summary, psychometric testing using the Wechsler memory scale (1945) has shown a selective memory defect for relatively long-term recall among the group of firemen who were clinically thought to be still suffering from organic cerebral impairment four years after the fire.

\section{Discussion}

A neurological syndrome is described in a group of men exposed to high concentrations of TDl for several hours. Acute symptoms in those most heavily exposed consisted of nausea, euphoria, ataxia, and loss of consciousness with confusion and amnesia in some. After a few days those acutely affected and some others complained of headache, poor memory, and difficulty in concentration which at times led to odd behaviour. These symptoms were at their worst after two weeks and then improved. Memory difficulties persisted in many, even up to four years later. Some also complained of personality change with irritability, depression, and loss of sociability. Except for those with complicating psychiatric features, the residual disorder was mild and subjective, and did not seriously interfere with their mode of life.

Respiratory complications have previously been reported in men chronically exposed to TDI during their work. There have been no previous reports of neurological complications. Two questions must be asked. Is the syndrome described an organic disorder or could it be a manifestation of mass hysteria or compensation neurosis? Secondly, is TDI responsible, or might some other toxic factor be the cause?

There have been some difficulties in establishing whether the disorder has an organic basis. Abnormal physical signs on neurological examination have been few, although some of the most severely affected men did have mild ataxia for a few weeks after the fire. Electroencephalograms were normal in the men on whom this examination was performed. This, however, does not exclude the diagnosis of a mild encephalopathy.
The memory defect for relatively long-term recall demonstrated in the groups of men who were still affected after four years favours an organic disorder. The similarity of symptoms in all except those with complicating psychiatric features also suggest a type of encephalopathy. Delayed effects during the first few days after the fire were in some instances initially noticed by someone other than the patient himself. Several men complained of symptoms independently, unaware that others were similarly affected, and were relieved to find that others were involved. They were all improving and a number thought they had recovered completely at a time when most medical interest was taken in the situation. Several of the men complained of continuing symptoms even after compensation was settled and there appeared to be no likelihood of further legal action. All these points favour an organic disorder.

The syndrome described is not typical of a mass hysterical reaction. The previous personalities of most of the West Country firemen were stable and sound, and their behaviour during investigation was matter-of-fact. They displayed no more anxiety than would be expected in this situation. The group affected is thus different from groups in which mass hysterical reactions have been described in the past, usually schoolgirls (Moss and McEvedy, 1965). Their behaviour at interview and good work record despite their complaints make then quite unlike patients with accident neurosis (Miller, 1961). In most of the men residual effects interfered little with their life and they were able to compensate well for their minor disabilities. In a group of this size it would be expected that psychiatric disabilities would emerge in a few and the recognition of such may be taken as further evidence in favour of an organic disorder in the remainder.

Many toxic gases may be generated during fires of all types. It is recognized that carbon monoxide is the most important of these and that the major factors in fire fatalities are exposure to carbon monoxide, anoxia, and hyperthermia (Kimmerle, 1974). During the incident described there is no evidence that the fumes were sufficiently dense for any of the men to have become anoxic, or that they suffered from hyperthermia. Exposure to other chemicals might have occurred and chemicals which were present in the factory are listed by 
Axford et al. (1976). None of these alone are known to produce a syndrome such as the one described. They cannot be excluded for certain, however, as in the intense heat during the fire a toxic combination of these chemicals or their breakdown products might have occurred. Some of the affected men were involved in cleaning-up operations the morning after the fire, rather than during the fire itself. At this stage carbon monoxide fumes are unlikely to have remained in the building. It also seems unlikely that small amounts of any other toxic substance which might have been liberated during the fire would have lingered in the gutted building overnight. On the other hand, large quantities of TDI remained on the floor of the building after the fire had been extinguished. Thus, although proof that TDI was responsible for the neurological syndrome described is lacking, it appears that the men affected had in common a greater exposure to TDI than those unaffected.

We are grateful to a number of people for their help and co-operation while this study was being carried out, particularly Dr T. L. H. Shore, who saw several of the men within a few days of the fire and at intervals subsequently; Dr J. W. Warboys, for the EEG reports; Dr D. G. Griffiths for advice about psychometric testing; Dr P. D. Oldham for help with the statistical analysis; Dr Theobald and the Devon fire service for their willing co-operation in enabling the control psychometric data to be collected, and especially to the Somerset fire service for their most generous and long suffering help in enabling these reviews to be carried out.

\section{References}

Axford, A. T., McKerrow, C. B., Parry Jones, A., and Le Quesne, P. M. (1976). Accidental exposure to isocyanate fumes in a group of firemen. British Journal of Industrial Medicine, 33, 65-71.

Fuchs, S. and Valade, P. (1951). Étude clinique et expérimental sur quelques cas d'intoxication per de desmodur T (di-isocyanate de toluylene 1-2-4 et 1-2-6). Archives des maladies professionnelles, 12, 191-196.

Gandevia, A. (1963). Studies of ventilatory capacity and histamine response during exposure to isocyanate vapour in polyurethane foam manufacture. British Journal of Industrial Medicine, 20, 204-209.

Kimmerle, G. (1974). Aspects and methodology for the evaluation of toxicological parameters during fire exposure. Journal of Fire and Flammability. Combustion Toxicology, 1, 4-51.

McKerrow, C. B., Davies, H. J., and Parry Jones, A. (1970). Symptoms and lung function following acute and chronic exposure to tolylene diisocyanate. Proceedings of the Royal Society of Medicine, 63, 376-382.

Miller, H. (1961). Accident neurosis. British Medical Journal, 1, 919-925.

Moss, P. D. and McEvedy, C. P. (1966). An epidemic of overbreathing among schoolgirls. British Medical Journal, 2, 1295-1300.

Munn, A. (1965). Hazards of isocyanates. Annals of Occupational Hygiene, 8, 163-169.

Wechsler, D. (1945). A standardized memory scale for clinical use. Journal of Psychology, 19, 87-95.

Received for publication 15 January 1975

Accepted for publication 24 June 1975 